\title{
Clinical and Demographic Profile of Diarrheal Patients of Pediatric Age: A Cross-Sectional Study
}

\author{
Ekta Acharya ${ }^{(1)}$ \\ Assistant professor, Department of Paediatrics, Gujarat Adani Institute of Medical Science, Bhuj, Kutch, Gujarat, India.
}

\section{Abstract}

Background : Sometimes, diarrhea may co-exist with vomiting, fever, abdominal pain, etc. depending upon its etiology. Diarrheal diseases can also lead to significant malnutrition and dehydration. Thus, at the tertiary care center, a study was conducted with an aim to center on the clinical and sociodemographic profile of infants and children presenting with acute diarrhea. Subjects and Methods: It was a prospective, observational clinical study that began after obtaining approval from the Institutional Ethics Committee. It was conducted at the Department of Pediatrics, Gujarat Adani Institute of Medical Science, Bhuj, Kutch for a period of 2 years. The sample size was 200 with 2 groups A and B having 100 patients each. Accordingly, their clinical and demographic profile was also noted and studied in 2 groups. Various parameters analyzed were age and gender distribution, chief complaints, feeding practices, nutritional status and assessment of dehydration. Results: Mean age \pm S.D were $(2.25 \pm 1.40)$ and (2.49 \pm 1.39$)$ years in group A and B respectively. Exclusive breastfeeding (EBF) for 6 months was given in a large no. of group A and B patients i.e. $52(52 \%)$ and 58(58\%) respectively. Few others were given for 4 , 5 , or 7 months. Maximum patients 58 $(58 \%)$ of A and $52(50 \%)$ of B group had no dehydration whereas remaining 42 (42\%) and 48 (48\%) patients had some dehydration respectively. Conclusion: Fever and vomiting were the complaints mainly regularly linked with diarrhea. a bit fewer than half of the children under research had some-dehydration. Greater parts of the patients were completely breastfed for six months.

Keywords: Children, Dehydration, Diarrhea, Vomiting

Corresponding Author: Ekta Acharya, Assistant professor, Department of Paediatrics, Gujarat Adani Institute of Medical Science, Bhuj, Kutch, Gujarat, India.

E-mail: drektathacker@hotmail.com

Received: 30 August 2020

Revised: 21 October 2020
Accepted: 27 October 2020

Published: 28 December 2020

\section{Introduction}

Diarrhea is distinct as, "passageway of 3 or further loose or liquid stools per day or further common way than is regular for the human being. ${ }^{[1,2]}$ The pediatric diarrhoeal disease still causes 800000 deaths per year internationally. ${ }^{[3,4]}$ Nonetheless, diarrhea-linked mortality is lessening worldwide by $4 \%$ annually; though, the decline in occurrence is diffident. It is measured that annual diarrhea accounts for about 2.5 billion cases in children less than 5 years old, affecting up to $60 \%$ of travelers to some lowincome areas. ${ }^{[5,6]}$ Furthermore, dissimilar diarrhea-related severe squeal have been described, including GuillainBarre syndrome, hemolytic uraemic syndrome (HUS) and reactive arthritis. ${ }^{[7]}$ Diarrhoea can last numerous days and can depart the body lacking the water and salts that are essential for endurance. Formerly, for the majority of people, severe dehydration and fluid loss were the chief causes of diarrhea deaths. Currently, further reasons such as septic bacterial infections are probable for a rising amount of all diarrhea-linked deaths. Sometimes, diarrhea may co-exist with vomiting, fever, abdominal pain, etc. depending upon its etiology. Diarrheal diseases can also lead to significant malnutrition and dehydration. Repeated attacks of diarrhea, infections, poor hygiene, etc. may be responsible for such outcomes. ${ }^{[8]}$ Basically, each diarrheal episode deprives the child of nutrition along with fluid loss, thus aggravating the severity of malnutrition and dehydration. Thus, at the tertiary care center, a study was conducted with an aim to focus on the clinical and sociodemographic profile of infants and children presenting with acute diarrhea. The results from this study will help in a better understanding of acute diarrhea in the pediatric age group of a particular geographical region. ${ }^{\text {[9] }}$

\section{Subjects and Methods}

It was a prospective, observational clinical study that began after obtaining approval from the Institutional Ethics Commit- 
tee. It was conducted at the Department of Pediatrics, Gujarat Adani Institute of Medical Science, Bhuj, Kutch for a period of 2 years. The sample size was 200 with 2 groups A and B having 100 patients each. Written consent of the patient's parents or guardian was obtained on an informed consent form in their respective vernacular language. It was followed by data collection a case record form. Only those infants and children who fulfilled inclusion criteria such as those aged between 6 months - 5 years, suffering from acute diarrhea and presenting to the Pediatric Department at this set-up for treatment; were included in the study. Those with comorbid conditions or admitted to the PICU were excluded. Here, patients were alienated into 2 groups according to the probiotic preparation being administered. Accordingly, their clinical and demographic profile was also noted and studied in 2 groups. Various parameters analyzed were age and gender distribution, chief complaints, feeding practices, nutritional status and estimation of dehydration.

\section{Statistical analysis}

The data was accumulated and entered in a worksheet computer program and then exported to data SPSS version 15. For all tests, confidence level and level of significance were set at $95 \%$ and $5 \%$ correspondingly.

\section{Results}

The mean, age for group A patients was $2.25 \pm 1.40$ years. A majority of 51 were toddlers. Similarly, for group B patients mean age was $2.49 \pm 1.39$ years. Here also, 42 patients were toddlers. The remaining were infants and pre-school children. Out of 100 patients in group A, 51 (51\%) males exceeded $49(49 \%)$ females, with a male: female (M: F) ratio of 1.02: 1. Similarly in the case of Exclusive breast-feeding: Exclusive breastfeeding (EBF) for 6 months was given in a large no. of group A and B patients i.e. $52(52 \%)$ and 58(58\%) respectively. Few others were given for 4,5 , or 7 months. [Table 2] Almost $36(36 \%)$ and $30(30 \%)$ patients in groups $\mathrm{A}$ and $\mathrm{B}$ respectively had continued breastfeeding during the study. In the remaining 64 (64\%) and 70 (70\%) group A and B patients respectively, breastfeeding was carried out till 1, 1.5, or 2 years. [Table 3]

In group A, a majority of 54 (54\%) patients were not given bottle feeding while the remaining 46 (46\%) were given. Almost $60(60 \%)$ patients were not given bottle-feeding whereas $40(40 \%)$ were given in group B. Maximum patients $58(58 \%)$ of A and $52(50 \%)$ of B group had no dehydration whereas remaining $42(42 \%)$ and $48(48 \%)$ patients had some dehydration respectively. [Table 4]

In group $\mathrm{A}$, a maximum of 28 patients had no dehydration and malnutrition while 24 had no dehydration but mild malnutrition. Some dehydration with no malnutrition was noted in 13 patients while 14 and 15 patients with some dehydration had mild and moderate malnutrition respectively as shown in Table 7. In group B patients with no dehydration; 2821 and 3 patients had no, mild and moderate malnutrition respectively. In patients with some dehydration, 12 patients had moderate malnutrition while 16 had mild and 20 had no malnutrition.

\section{Discussion}

The present study covered the clinical and demographic profile of infants and children aged 6 months to 5 years and presenting with chief complaints of acute diarrhea to the Department of Pediatrics. ${ }^{[10]}$ In our study, analysis of the socio-demographic profile of the study population showed that a large no. of patients belonged to the toddler age group in groups A and B respectively. Accordingly, their Mean age \pm S.D were $(2.25 \pm 1.40)$ and $(2.49 \pm 1.39)$ years in group A and B respectively. Infants and preschool children were relatively lesser affected in both study groups. Gender distribution in our study showed male preponderance in both the groups as mentioned in table 1 . Lee et al, ${ }^{[11]}$ in their research total number of 27 children were assessed. Male: female ratio 1.1:1. Aluntas et al, ${ }^{[12]}$ done their study on 70 children of which $52 \%$ female, $48 \%$ male. Infants and preschool children again had a greater number of males than females. Chen et al and Heuilan et al in their respective studies noted male predominance and the majority of the patients (84\%) were between 6 months to 2 years. ${ }^{[13,14]}$ Among the presenting complaints of diarrheal patients, vomiting, as well as fever, was noted in a majority. Similar observations were examined in the studies performed by Francavilla $\mathrm{R}$ et al, where $65 \%$ of patients had vomiting and $51 \%$ of study participants had fever associated with diarrhea. ${ }^{[15]}$ This may be due to higher incidences of infective origin diarrhea among patients. Depending upon the loss of fluid, fewer patients in both, groups A and B, also presented with symptoms of refusal to feed and decreased urinary output each. Kumar $\mathrm{M}$ et al, ${ }^{[16]}$ described after vomiting and fever, (47.7\%) with decreased oral intake and $12(27.3 \%)$ with decreased urine output along with loose stools were noted. Exclusive breastfeeding (EBF) for an ideal 6 months was noted in the highest no. of study participants in groups A \& B. Remaining patients showed EBF for 4, 5, or 7 months. The total duration of 1.5 years of breastfeeding was noted in a maximum 32 (32\%) group A and $40(40 \%)$ group B patients while in almost $36 \%$ and $30 \%$ patients of group $\mathrm{A}$ and $\mathrm{B}$, it was still continued during the study period. Reifen et al, ${ }^{[17]}$ performed research on 3 children with prolonged, watery diarrhea ongoing in premature infancy, they establish dissimilar histologic and ultrastructural features that they elected tufting enteropathy. Termination of enteral feedings reduce the quantity of diarrhea to fewer than $500 \mathrm{ml}$ per day in all 3 patients, 2 of 3 children accomplished 
Table 1: Gender distribution of patients

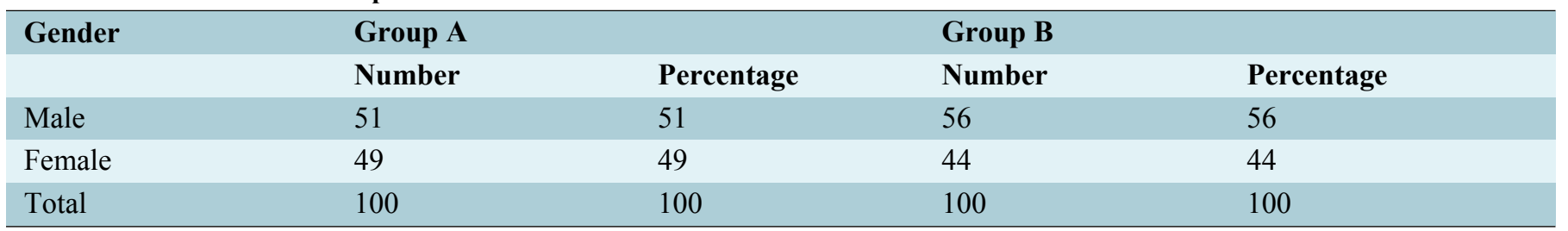

Table 2: Duration of exclusive breast-feeding among diarrheal patients

\begin{tabular}{lllll}
\hline Duration of exclusive breastfeeding (months) & Group A & & \multicolumn{2}{c}{ Group B } \\
& Number & Percentage & Number & Percentage \\
04 & 18 & 18 & 10 & 10 \\
05 & 22 & 22 & 18 & 18 \\
06 & 52 & 52 & 58 & 14 \\
07 & 8 & 8 & 14 & 14 \\
\hline
\end{tabular}

Table 3: Severity of malnutrition and degree of dehydration in group $A$

\begin{tabular}{llll}
\hline Duration of exclusive breastfeeding & Degree of dehydration & & Total no of patients \\
\hline No & No & Some & 41 \\
\hline Mild & 28 & 13 & 38 \\
Moderate & 24 & 14 & 21 \\
Total & 6 & 15 & 100 \\
\hline
\end{tabular}

Table 4: Severity of malnutrition and degree of dehydration in group $B$

\begin{tabular}{llll}
\hline Duration of exclusive breastfeeding (months) & \multicolumn{2}{l}{ Degree of dehydration } & \multicolumn{2}{c}{ Total no of patients } \\
\hline No & No & Some & 40 \\
Mild & 28 & 12 & 37 \\
Moderate & 21 & 16 & 23 \\
Total & 3 & 20 & 100 \\
\hline
\end{tabular}

standard enlargement velocity in equal height and weight within 6 months; equally, these children were still reliant on TPN at home at ages 8.5 and 6 years, correspondingly. In diarrheal patients of our study, nutritional status was also observed and the results showed that those 28 group A and 28 group B patients who had normal nutritional status had no dehydration as well. Similarly, moderate malnutrition noted in 15 groups A and 20 group B patients had some dehydration. Contradictory to that, only 6 in group A and 3 in group $\mathrm{B}$ had moderate malnutrition but no dehydration. This is similar to the observations from Francavilla $\mathrm{R}$ et al study where the control and placebo groups had the majority of patients with no dehydration i.e. 25 and 26 respectively. ${ }^{[15]}$ Literature also suggests that malnutrition can predispose a child to diarrhea and severity may be slightly higher in those patients causing fluid loss and dehydration. The knowledge of resistance patterns of common etiological agents in the local area can help practitioners to choose an adequate antimicrobial drug to start empirical therapy in a patient with severe diarrhea without knowledge of a specific pathogen. This study can also be carried out at regular intervals to study any variations in the pattern of clinical profile of such patients. The effectiveness of treatment in these patients can also be studied in the future. Dehydration and malnutrition can also be prevented through patient education, availability of safe drinking water, adequate sanitation and hygiene. 


\section{Conclusion}

Fever and vomiting were the complaints nearly all often linked with diarrhea. A slight fewer than half of the children under research had some-dehydration. Almost half of the study population goes to the toddler age group. Proportional studies linked to contributory agents like bacteria, viruses should be specified more significance since they assist in disease preclusion tactics. Role of Information Education and Communication is extremely significant concerning diarrhoeal and therefore should be prioritized.

\section{References}

1. Sweetser S. Evaluating the Patient With Diarrhea: A CaseBased Approach. Mayo Clin Proc. 2012;87(6):596-602. Available from: https://dx.doi.org/10.1016/j.mayocp.2012.02. 015.

2. Schiller LR. Definitions, pathophysiology, and evaluation of chronic diarrhoea. Best Pract Res Clin Gastroenterol. 2012;26(5):551-62. Available from: https://dx.doi.org/10. 1016/j.bpg.2012.11.011.

3. Lanata CF, Fischer-Walker CL, Olascoaga AC, Torres CX, Aryee MJ, and REB. Global Causes of Diarrheal Disease Mortality in Children $<5$ Years of Age: A Systematic Review. PLoS One. 2013;8(9):e72788-e72788. Available from: https: //dx.doi.org/10.1371/journal.pone.0072788.

4. Black R, Fontaine O, Lamberti L, Bhan M, Huicho L, Arifeen $\mathrm{SE}$, et al. Drivers of the reduction in childhood diarrhea mortality 1980-2015 and interventions to eliminate preventable diarrhea deaths by 2030. J Glob Health. 2019;9(2):020801. Available from: https://dx.doi.org/10.7189/jogh.09.020801.

5. N JG. Epidemiology, etiology and pathophysiology of traveler's diarrhea. Digestion. 2006;73(S1):102-108. Available from: https://doi.org/10.1159/000089785.

6. Ruiz J, Olivares SV, Julian RD, Mensa L, Puyol L, Puente S. Detection of the eae gene in Escherichia coli isolates causing traveller's diarrhea both in atypical EPEC and in non-EPEC, non-EHEC isolates. Brit Trav Health Assoc J. 2008;12:47-48.

7. Walker CLF, Rudan I, Liu L, Nair H, Theodoratou E, Bhutta ZA, et al. Global burden of childhood pneumonia and diarrhoea. The Lancet. 2013;381(9875):1405-1416. Available from: https://dx.doi.org/10.1016/s0140-6736(13)60222-6.

8. Patwari AK. Diarrheal Diseases. IAP Textbook of Paediatrics. Jaypee Brothers. 2002;p. 414-419.

9. Poo MI, Lee WS. Admission to hospital with childhood acute gastroenteritis in Kuala Lumpur, Malaysia. Med J Malaysia.
2007;62(3):189-93.

10. Yongsi HBN. Pathogenic Microorganisms Associated With Childhood Diarrhea in Low-and-Middle Income Countries: Case Study of Yaoundé - Cameroon. Int J Environ Res. 2008;5(4):213-229. Available from: https://dx.doi.org/10. 3390/ijerph5040213.

11. Lee WS, Boey CCM. Chronic diarrhoea in infants and young children: Causes, clinical features and outcome. J Paediatr Child Health. 1999;35(3):260-263. Available from: https://dx. doi.org/10.1046/j.1440-1754.1999.00356.x.

12. Altuntaş B, Gül H, Yarali N, Ertan U. Etiology of chronic diarrhea. Indian J Pediatr. 1999;66(5):657-661. Available from: https://dx.doi.org/10.1007/bf02726245.

13. Chen JM, Ni YH, Hl C, Chary MH. Microbiology etiology of acute gastroenteritis in hospitalized children in Taiwan. $\mathrm{J}$ Formos Med Assoc. 2006;105(12):964-970. Available from: https://doi.org/10.1016/s0929-6646(09)60280-1.

14. Heulian HJ, Blackflow N. Enteric adenoviruses in children: Infection of the gastrointestinal tract; 1995.

15. Francavilla R, Lionetti E, Castellaneta S, Ciruzzi F, Indrio F, Masciale A. Randomised clinical trial: Lactobacillus reuteri DSM 17938 vs. placebo in children with acute diarrhoea - a double-blind study. Aliment Pharmacol Ther. 2012;36(4):363369. Available from: https://dx.doi.org/10.1111/j.1365-2036. 2012.05180.x.

16. Kumar M, Ahmed M, Vohra P, Warsi S. To compare the efficacy of two probiotics in acute non bloody diarrhea. Int J Contemp Pediatr. 2016;4(1):123-123. Available from: https: //dx.doi.org/10.18203/2349-3291.ijcp20164590.

17. Reifen RM, Cutz E, Griffiths AM, Ngan BY, Sherman PM. Tufting enteropathy: a newly recognized clinicopathological entity associated with refractory diarrhea in infants. J Pediat Gastroent Nutr. 1994;18(3):379-385.

Copyright: (C) the author(s), 2020. It is an open-access article distributed under the terms of the Creative Commons Attribution License (CC BY 4.0), which permits authors to retain ownership of the copyright for their content, and allow anyone to download, reuse, reprint, modify, distribute and/or copy the content as long as the original authors and source are cited.

How to cite this article: Acharya E. Clinical and Demographic Profile of Diarrheal Patients of Pediatric Age: A Cross-Sectional Study. Asian J. Clin. Pediatr. Neonatol. 2020;8(4):5-8.

DOI: dx.doi.org/10.47009/ajcpn.2020.8.4.2

Source of Support: Nil, Conflict of Interest: None declared. 